J. Lake Sci. (湖泊科学), $2006, \mathbf{1 8}(5): 464-469$

http:// www. jlakes. org. E-mail: jlakes@ niglas. ac.cn

(c) 2006 by Journal of Lake Sciences

\title{
洪湖分蓄洪区洪水淹没风险动态识别与可能损失评估
}

\author{
Marco GEMMER ${ }^{1}$ ，王国杰 ${ }^{2,3 * *}$ ，姜 㣌 ${ }^{2}$ \\ ( 1 : 吉森大学地理研究所,吉森 德国) \\ (2: 中国科学院南京地理与湖泊研究所,南京 210008) \\ (3: 中国科学院研究生院, 北京 100039)
}

\begin{abstract}
摘 要: 全球气候变化和社会经济快速发展, 使长江流域面临越来越严重的防洪压力. 在长江流域开展洪水淹没风险识 别与洪水损失评估工作, 对于长江流域洪水风险管理具有重大意义. 本项研究以洪湖分蓄洪区为案例, 采用基于 GIS 栅 格数据整合于 Arcview3. $\mathrm{x}$ 的二维水文 - 水动力学模型进行洪水淹没风险动态识别, 并且根据土地利用分类及其单位面积 价值, 建立洪水淹没损失函数, 进行洪水淹没动态损失评估, 建立了东洪湖分蓄洪区洪水淹没动态损失数据库, 为东洪湖 分蓄洪区的合理利用提供定量科学依据. 洪水淹没动态风险识别基于数字高程模型进行,采用修正的 1998 年夏季洪水水 位 - 时间水文过程线对模型参数进行调整,并以地面糙率反映不同地表覆盖形态对洪水演进过程的影响.
\end{abstract}

关键词: 洪水风险管理; 淹没风险识别; 可能损失; 洪湖分蓄洪区

\section{Dynamic inundation risk identification and estimation of the potential loss in Honghu flood diversion area, China}

\author{
Marco GEMMER $^{1}$, WANG Guojie ${ }^{2,3} \&$ JIANG Tong ${ }^{2}$ \\ (1: Department of Geography, Giessen University, Germany) \\ (2: Nanjing Institute of Geography and Limnology, CAS, Nanjing 210008, P. R. China) \\ (3. Graduate School of the CAS, Beijing 100039, P. R. China)
}

\begin{abstract}
Under the background of global change and the rapid development of economy, the Yangtze River basin is confronted with rising pressure to prevent flood. The identification of inundation risks and the evaluation of potential flood losses are of great significance in the Yangtze river basin. This study performs the identification of the inundation risk in Honghu flood diversion area with a hydrological-hydraulic model based on raster data integrated into Arcview3. x. It processes an evaluation of the potential loss in terms of land use types and damage functions, and finally builds an dynamic database of potential loss which can serve as scientific base for the management of Honghu flood diversion area. The identification of inundation risks is carried out based on a digital elevation model, calibrated with the waterstage-time curve derived from the summer flood in 1998 and manning roughness of each land use type.
\end{abstract}

Keywords: Flood risk management; inundation risk identification; potential loss; Honghu flood diversion area

长江流域是我国洪涝灾害最为严重的区域,洪涝灾害严重威胁人民的生命财产安全和社会稳定发展. 据研究,21 世纪长江流域的增温可能达到 $2.7^{\circ} \mathrm{C}$, 降水量可能增加 $10 \%$, 径流量将增加 $37 \%$, 降水极值事件 也有可能更为频繁发生 ${ }^{[1,2]}$, 长江流域面临越来越重的防洪压力. 世界各国防洪经验表明,单纯依靠工程措 施并不能有效防治洪水;洪水防治,必须实行工程措施和非工程措施并举的新思路. 总结世界各国防洪实

* 国家自然科学基金 (40371112), 中国科学院知识创新工程重要方向项目性项目 (KZCX3 - SW - 331), 水文水资源 和水利工程科学国家重点实验室开放基金(2004405511) 联合资助. $2005-05-27$ 收稿; 2005-08-03 收修改稿. Marco Gemmer,男,博士, 现于意大利欧洲研究中心工作.

** 通讯作者:王国杰,E-mail: wgjie1976@163.com. 
践经验, 在洪水防治中必须增加风险管理的新方略 ${ }^{[3]}$. 流域洪水淹没风险动态识别及其可能损失评估是流 域洪水风险管理的前提和基础. 目前世界各国对该项工作非常重视, 开展了大量相关研究, 取得了一些具 有借鉴意义的成果 ${ }^{[4-6]}$. 在中国, 对该领域的研究尚处于起步阶段, 尤其是洪水淹没风险的识别还处于静 态层面. 日渐增长的洪水压力要求必须对长江流域的洪水淹没动态风险识别与可能损失评估工作给予足 够重视. 分蓄洪区是长江流域最重要的防洪措施, 是最易遭受洪水灾害的区域. 洪湖分蓄洪区是长江中游 最重要的分蓄洪区之一, 做好洪湖分蓄洪区的洪水淹没风险识别与可能损失评估工作, 为其合理规划与科 学管理提供定量科学依据, 是长江流域洪水风险管理的重要基础工作.

\section{1 研究区与研究方法}

\section{1 研究区}

洪湖分蓄洪区是中国最早设计的分蓄洪区之一, 也是长江流域最大的分蓄洪区, 位于湖北省监利市和 洪湖市内, 占地面积 $2783 \mathrm{~km}^{2}$, 设计蓄洪容量 $177 \times 10^{8} \mathrm{~m}^{3}$. 洪湖分蓄洪区地处洪泛平原, 农业条件优异, 1949 年以来尤其是改革开放以来农业迅速发展, 带动人口与相关产业的迅速集聚. 社会财富的快速增长, 使承灾体的潜在可能损失不断增大, 也使得未来风险管理对风险评估工作提出了更为迫切的要求. 根据湖 北省防汛抗旱总指挥部的防洪管理预案, 洪湖分蓄洪区将被划分为东、中、西 3 个部分. 西洪湖分蓄洪区包 括从长江到洪湖部分; 中洪湖分蓄洪区包括洪湖和洪湖市, 一直延伸到洪湖东 $10 \mathrm{~km}$ 处; 东洪湖分蓄洪区包 括从中洪湖分蓄洪区一直延伸到长江的低洼地区; 其中, 东洪湖分蓄洪区是社会财富最为集中的部分, 也是 最受管理当局关注的部分. 本文选取东洪湖分蓄洪区作为试验区 (面积 $825 \mathrm{~km}^{2}$, 图 1), 进行洪水淹没风险 动态识别及其可能损失评估.

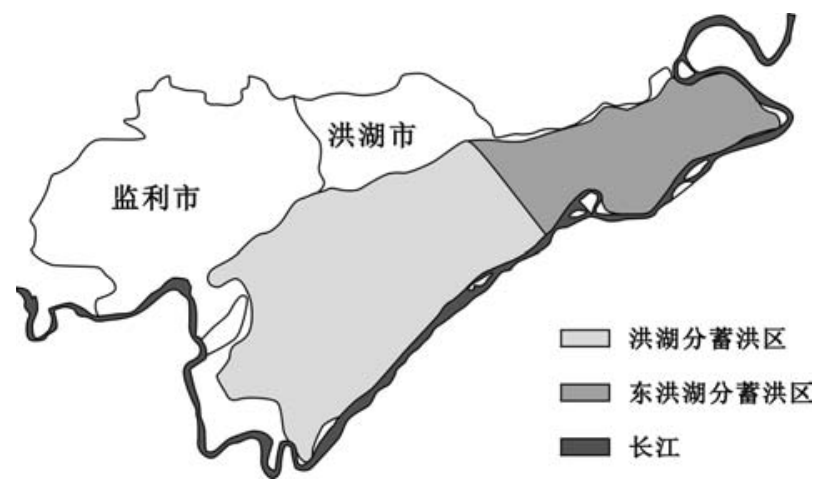

图 1 研究区位置

Fig. 1 The location of the study area

\section{2 研究方法}

洪水淹没风险识别的基础是洪水淹没风险制图. 常用洪水淹没风险制图方法, 主要有地理地貌学方 法、历史洪水法和水文 - 水动力学模型法. 随着洪水风险管理工作的深人开展, 尤其是对洪水淹没风险制 图提出动态性要求以来, 这些常规洪水淹没风险制图方法已经不能满足日益精细的洪水风险管理工作的需 要. 20 世纪 90 年代以来, 人们最感兴趣的是采用与 GIS 整合的水文 - 水动力学模型 ${ }^{[7,8]}$, 通过数值模拟来 计算洪水的可能淹没范围、深度及其历时特征,并且在理论取得了一定成果 ${ }^{[9-15]}$. 但是, 目前国内对该方面 的研究尚处于探索阶段,尚未形成一套成熟有效、易于推广的模式. 基于 GIS 栅格数据进行水文 - 水动力 学建模是实现两者整合的有效手段. 水文 - 水动力学模型与 GIS 整合的最大优点是在于两个方面:一是为 水文 - 水动力学模型的有限元、有限差分等解法提供栅格数据基础, 二是模拟结果的可视化表达. 基于 GIS 栅格数据, 德国 Geomer 公司开发了内嵌于 GIS 平台 ArcView3. x 的扩展模块 FloodArea, 专门用于洪水演进 模拟与动态风险制图. FloodArea 采用 ArcGRID 数据格式, 基于数字高程模型进行水文 - 水动力学建模, 充 分考虑了地形坡度和不同地表覆盖形态下地面鋉度对洪水演进形态的影响;洪水以给定水位和给定流量两 种方式进人模型, 并可根据水文过程线进行实时调整, 可视化表达流向、流速和淹没水深等水文要素的时空 
物理场 ${ }^{[16]}$, 为我们洪水淹没风险动态制图提供了有效工具.

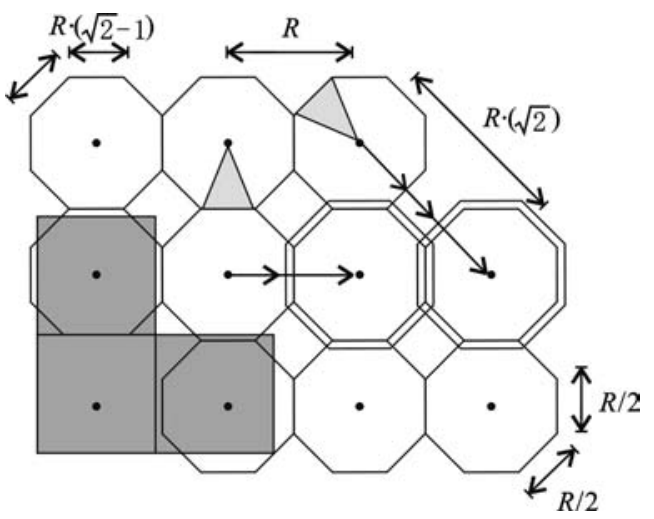

图 2 FloodArea 计算方法

Fig. 2 The calculation method of FloodArea

该模块充分利用了 GIS 栅格数据在水文 - 水动力学 建模上的优势, 实现 GIS 与水文一水动力学模型的数据 融合. 以栅格为基本单元,洪泛区的计算基于二维非恒定 流水动力学模型, 用 Manning-Strickler 公式计算每个栅格 与周围的 8 个栅格之间的水量交换. 不同栅格单元之间 的水量交换在虚拟 8 边形栅格(周长与原栅格相同)基础 上进行, 并且规定水流宽度为 $1 / 2$ 栅格宽度. 水流方向由 每个栅格与邻近 8 个栅格之间的坡度决定. 由于栅格中 心点到对角单元中心点的距离大于横向或纵向相邻栅格 的距离, 对角栅格单元的算法被赋予了不同的长度 ${ }^{[16]}$.

本项研究的焦点在于对洪水所造成的直接经济损失 进行估算. 淹没损失估算的依据是洪水期土地覆盖类型 及其单位面积的价值. 洪水造成的可能损失,与洪水淹没 深度密切相关,本研究通过走访调查等方式建立了不同 土地利用类型对于不同洪水淹没深度的财产损失率, 以反映两者关系. 把上文所获的不同时相洪水演进模 拟结果, 与栅格化的土地利用图分别进行空间叠加, 利用地图代数语言编写既定财产损失函数, 实现不同时 相洪水淹没损失的估算 ${ }^{[6,17]}$. 研究技术路线如图 3. 该种洪水淹没风险动态识别与可能损失评估方法已经 在德国莱茵河流域广泛应用, 取得良好的社会、经济效益 ${ }^{[18]}$.

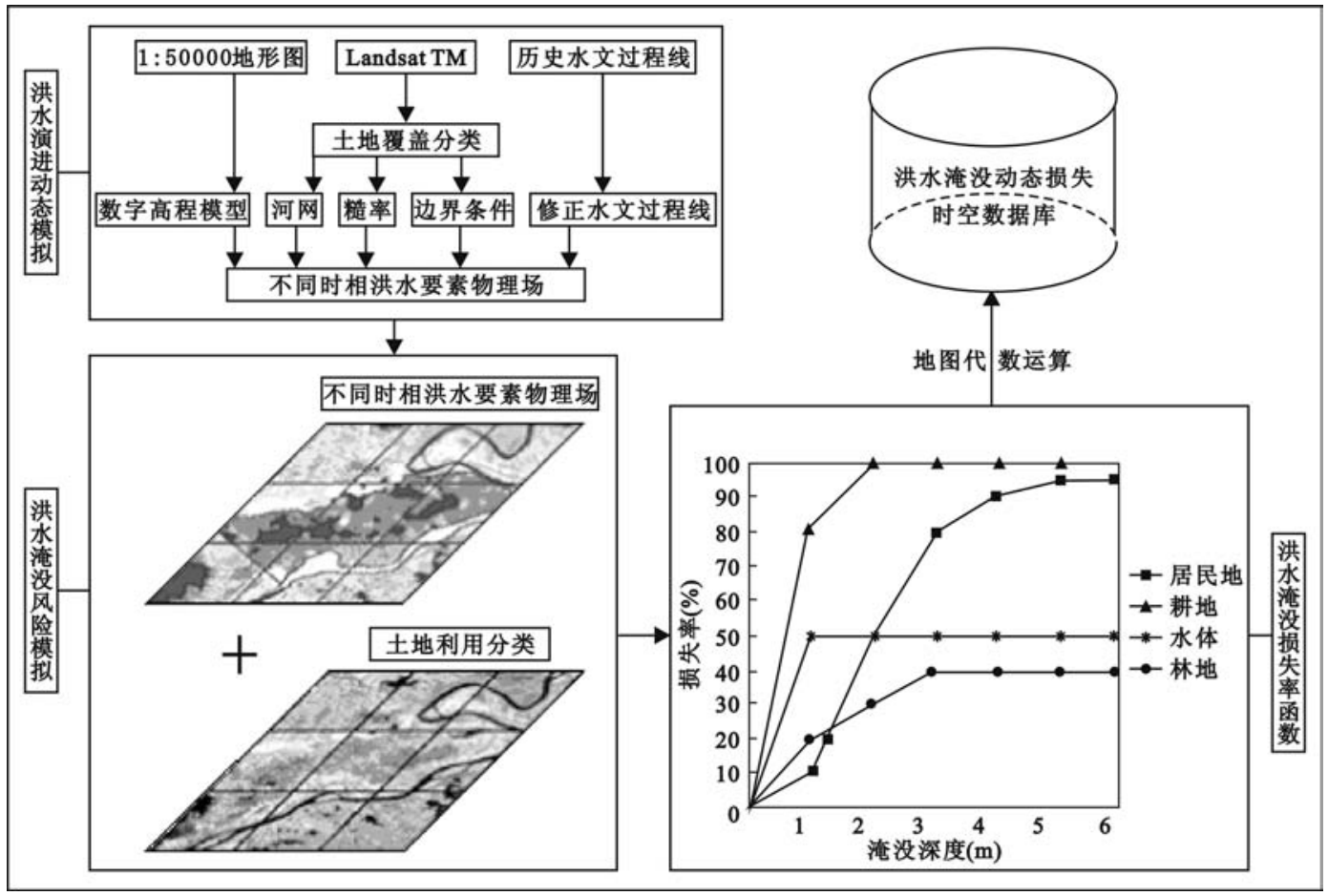

图 3 本项研究技术路线

Fig. 3 The methodology of this study 


\section{2 洪水淹没动态风险识别}

洪水淹没动态风险识别的基础是洪水演进数值模拟. 本项研究中洪水演进数值模拟基于 GIS 栅格数 据进行,所有空间数据以 ArcGRID 格式输人模型, 栅格分辨率 $100 \mathrm{~m} \times 100 \mathrm{~m}$. 输人变量具体包括:

(1) 数字流域模型: 采用 1:50000 地形图高程点进行 Kriging 插值,并利用 ESRI 公司生产的水文分析 模块 ArcHydro 进行填洼, 获得数字流域模型.

(2) 阻水建筑物: 其作用在于限定洪水演进模拟的边界条件. 采用 1:50000 工程设计图与遥感影像确 定东洪湖分蓄洪区外围堤坝.

(3) 洪水人口: 在洪湖分蓄洪区初始设计方案中,有两个泄洪闸,一个位于分蓄洪区西部 1954 年洪水 破圩处, 另一个位于龙口镇. 龙口泄洪闸宽 $1800 \mathrm{~m}$, 一旦分洪, 洪水将于龙口泄洪闸进人东洪湖分蓄洪区.

(4) 水文过程线: 在本项研究中,洪水以水位形式进人分蓄洪区. 为了反映长江水位变化对东洪湖分蓄 洪区内洪水演进形态的影响, 需要定制水文过程线以实时调整人流水位. 龙口泄洪闸没有实测水位, 水文 过程线需要通过其它水文站的实测数据推求. 龙口泄洪闸上游有洛山水文站, 下游有汉口水文站. 通过研 究发现,上下游两个水文站的水位 - 时间过程线形状在研究时段内非常相似,两者中任何一个水文站的水 位 - 时间过程线都可以用做水文过程线. 本文选取 1998 年夏季洛山水文站 8:00 实测水位推求龙口泄洪闸 水位. 根据其水文过程线特征, 选取洪峰持续时段即 7 月 29 日到 8 月 30 日的水文过程线为参考水位. 根 据长期观测经验以及既有研究成果, 长江洪水期洪水水位的坡降为 $2.5 \mathrm{~cm} / \mathrm{km}$, 龙口泄洪闸距洛山水文站 $58 \mathrm{~km}$, 在洛山站水文过程线线的基础上减去 $1.45 \mathrm{~m}$, 获得龙口泄洪闸的参考水位 - 时间水文过程线.

(5) 地面楉度 : 不同的土地覆盖形态,会对洪水演进形成不同的阻率. 为反映不同阻率对洪水演进形 态的影响, 需要在模型中加人地面䊁度. 本文选用 2000 年 1 月 13 日 Landsat7 ETM123/39 影像,运用监督分 类中最大似然分类法把东洪湖分蓄洪区的土地覆盖状况分为居民地、水体、旱地、水浇地、林地 5 种类型. 经检验解译精度达 $90 \%$, 满足研究需要. 以土地覆盖分类为基础, 结合经验与 Manning-Strickler 公式确定地 面粘度 (表 1 ).

表 1 土地利用分类及其䊅率

Tab. 1 The land use types and its manning roughness

\begin{tabular}{cccccc}
\hline 土地覆盖分类 & 居民地 & 水体 & 早地 & 水浇地 & 林地 \\
\hline Strickler 系数 & 12.5 & 33.0 & 28.0 & 20.0 & 12.0 \\
Manning 糙率 & 0.080 & 0.030 & 0.035 & 0.500 & 0.083 \\
\hline
\end{tabular}

本项研究以 $1 \mathrm{~h}$ 为时间步长进行洪水演进动态模拟,根据采用的水位 - 时间水文过程线模拟总时长为 $768 \mathrm{~h}(32 \mathrm{~d})$. 模拟结果以 ArcGRID 数据格式输出, 以 $1 \mathrm{~h}$ 为时间间隔记录了洪水演进过程中流速和淹没深 度的时空物理场, 并以矢量形式给出对应时刻任一栅格单元的洪水流向, 淹没深度的模拟精度控制在 $1 \mathrm{~cm}$ 之内. 把不同时相洪水演进模拟结果与土地利用现状图分别进行叠加运算,识别不同时相各种土地利用类 型的淹没风险, 建立洪水淹没风险动态数据库. 然后, 建立不同土地利用类型的洪水淹没损失率函数, 根据 各种土地利用类型单位面积的价值及其损失率函数, 进行洪水淹没损失评估, 最终建立洪水动态淹没风险 及其损失评估时空数据库.

\section{3 洪水淹没损失动态评估}

各种土地利用类型单位面积价值的估算,充分考虑洪湖分蓄洪区历年社会经济调查资料、2000 年人口 普查资料等社会经济信息, 分洪时期的主要作物、以及洪湖分洪区损失率指标. 基于 2002 年遥感影像数 据, 研究区土地利用可分为居民地、耕地、水体和林地 4 种类型. 据统计, 研究区现有居民 25.5 万人, 以从 事农业生产为主, 部分从事加工工业和第三产业. 居民地的价值估算, 综合考虑房屋迁建费用、私有大宗财 物、谷物以及衣物等的损失. 水体价值估算主要依据渔业产值,包括鱼、贝、虾、藕等种养业. 耕地价值估算, 
主要考虑夏秋季节收种的作物, 包括小麦、棉花、甘蔗、甘薯, 以及蔬菜等. 林地价值估算, 主要考虑木材、树 苗、以及鲜果价值. 基于洪水淹没风险动态数据库与各种土地利用类型单位面积价值, 参照不同地类的洪 水淹没损失率函数 (图 3 ), 进行研究区洪水淹没损失估算, 建立洪水淹没损失动态数据库. 在模拟 $23 \mathrm{~d}$ 后, 水文过程线到达最高点 $33.47 \mathrm{~m}$ (对应 1998 年夏季洪水中 8 月 20 日螺山站最高水位 $34.95 \mathrm{~m}$ ), 淹没面积达 最大值, 之后长江洪水水位降低, 分蓄洪区蓄水向长江回退, 此时洪水淹没损失也达到最大值. 模拟 $23 \mathrm{~d}$ 后 洪水淹没各种地类的面积及其造成的可能损失如表 2 .

表 2 各种土地覆盖类型洪水淹没损失估算

Tab. 2 Potential loss of each land use type

\begin{tabular}{cccc}
\hline 土地覆盖分类 & 单位面积价值 $\left(\right.$ 万元 $\left./ \mathrm{km}^{2}\right)$ & 淹没面积 $\left(\mathrm{km}^{2}\right)$ & 淹没损失 $($ 万元 $)$ \\
\hline 居民地 & 1292.7 & 92.04 & 118983 \\
耕 地 & 148.9 & 602.06 & 89677 \\
水 体 & 80.1 & 62.99 & 5052 \\
林 地 & 100.9 & 68.76 & 6941 \\
合计最大可能损失 $($ 万元 $)$ & - & - & 220653 \\
\hline
\end{tabular}

\section{4 结论与讨论}

1 ) 洪水淹没风险识别是进行淹没损失评估的基础. 目前国内洪水淹没风险识别尚处于以历史洪水为 依据的静态层面, 基本方法是通过对水面高程做差值运算获得洪水过程的水文特征. 在模拟过程中充分考 虑洪水演进的物理机制, 尤其是加人坡度、坡向的影响, 是当前研究的一个热点方向, 尚处于探索阶段. 虽 然一些研究者基于传统的网格单元进行水文 - 水动力学建模取得一些成果 ${ }^{[11-14]}$, 但是因为无法与高效的 GIS 平台结合, 在洪水风险管理的实践中往往难以发挥作用. 本项研究采用基于 GIS 栅格数据内嵌于 GIS 平台 ArcVIEW3. $\mathrm{x}$ 的二维水文-水动力学模型, 充分考虑了行洪过程的物理机制, 模拟 1998 年夏季洪水重 现时洪湖分蓄洪区的行洪过程, 识别其洪水淹没风险, 取得理想效果. 基于 GIS 栅格数据的水文 - 水动力 学模型,使洪水淹没风险识别与洪水损失评估工作从理论向实践迈了一大步.

2) 洪水淹没可能损失评估对于长期防洪规划具有重要指导意义. 国际上进行洪水淹没损失评估,最通 用的有两种途径:一是个体损失模型,即逐个估算承灾个体的可能损失; 二是根据保险公司所承保的财产数 额,对可能损失进行估算. 这两种国际上广泛接受的评估方法,目前在我国难以实现. 本项研究基于土地利 用分类及其单位面积财产价值, 构建洪水淹没损失函数, 进行洪水淹没损失评估, 是一种更为简易可行的通 用模式.

3) 本项研究在反演 1998 年洪水的基础上,以土地利用分类为依据,进行洪水淹没动态损失评估,建立 了洪湖分蓄洪区洪水淹没动态损失评估时空数据库. 该项研究成果可望为洪湖分蓄洪区的合理规划与使 用提供定量科学依据,其技术路线对相关工作在长江流域的开展也有一定借鉴意义.

\section{5 参考文献}

[1] 姜 形,施雅风. 全球变暖、长江洪灾与可能损失. 地球科学进展,2003,18(2):277 - 284 .

[2] Zhai P M, Sun A, Ren F, et al. Changes of climate Cxtremes in China. Climate Change, 1999, 42 : 203 218.

[3] 苏布达, 姜 形, 郭业友等. 基于 GIS 栅格数据的洪水风险动态模拟模型及其应用. 河海大学学报, $2005,33(4), 370-374$.

[4] Ahmad S, Simonovic S P. Integration of heuristic knowledge with analytical tools for the selection of flood damage reduction measures. Canadian Journal of Civil Engineering, 2001, (28) : 208 - 221.

[5] Manson S M, Ratick S J, Solow A R. Decision making and uncertainty: Bayesian analysis of potential flood 
heights. Geographical Analysis, 2002, 34(2):112 - 129.

[6] NRC. The impacts of natural disasters: a framework for loss estimation. Natural research council (NRC), National Academy Press, Washtington, 1999.

[7] Correia F, Rego F, Saraiva M, et al. Coupling GIS with hydrologic and hydraulic flood modelling. Water Resources Management, 1998, (12) : 229 - 249.

[8] Andre Z, Stephen W. Beyond Modeling: Linking models with GIS for flood risk management. Natural Hazards, 2004, 33(2) : $191-208$.

[9] 万洪涛,周成虎,万 庆等. GIS 技术支持下的洪水模型建模. 地理研究,2001,20(4):407 - 415 .

[10] 刘仁义,刘 南. 基于 GIS 的复杂地形洪水淹没区计算方法. 地理学报,2001,56(1):1-6.

[11] 葛小平, 许有鹏, 张 琪等. GIS 支持下的洪水淹没范围模拟. 水科学进展, 2002,13(4):456-460.

[12] 丁智雄,李纪人,李 琳. 基于 GIS 网格模型的洪水淹没分析方法. 水利学报,2004,(6):56-67.

[13] Hluchy L, AstalJ, Dobruck M, et al. Flood forecasting in a grid-computing environment. In: Wyrzykowski R, et al eds. Proc. of 5-th Intl. Conf. on Parallel Processing and Applied Mathematics PPAM2003, LNCS 3019, Springer, $2004: 831-839$.

[14] Boyle S J, Tsanis I K, Kanaroglou P S. Developing geographic information system for land use impact assessment in flooding conditions. Journal of Water Resources Planning and Management, 1998, 124 (2) : 89 -98 .

[15] Bates P D, De Roo A P J. A simple raster-based model for floodplain inundation. Journal of Hydrology, 2000,236 : $54-77$.

[16] Geomer. Floodarea-Arcview extension for calculating flooded areas, user manual, version 2.4, Geomer Heidelberg, 2002.

[17] Dutta D, Herath S, Musiake K. A mathematical model for flood loss estimation. Journal of Hydrology, $2003,227: 24-49$.

[18] Gemmer M. Decision support for flood risk management at the Yangtze River by GIS/RS-based flood damage estimation. Doctoral dissertation, University of Giessen University, Germany. Aachen : Shaker Publishing House, 2004. 